We identified a major shortfall in the provision of an effective and lifesaving treatment. Differences in the incidence of acute myocardial infarction across the country cannot explain the variation in clinical practice observed, and any error due to the use of thrombolytic agents for other conditions was probably small. The median treatment rate of five patients per 100000 each month suggests that 30000 patients are treated annually in England. If the highest rates that we found were achieved nation wide a further 60000 patients would be treated. Is this a realistic estimate of the shortfall?

The rate of infarction is not known accurately. The British Heart Foundation quotes 240000 each year in Great Britain based on pooled data (estimates range from 146000 to 362000 ). This is equivalent to 205000 infarcts in England. Almost half are immediately fatal, which corresponds with the crude death rate from myocardial infarction in England (nearly 90000 deaths in 1988). ${ }^{2}$ Most survivors attend hos- pital, and at least half are eligible for thrombolysis. ${ }^{4}$ From these estimates and our data we calculate that each year about 20000 (possibly as many as 60000 ) eligible patients do not receive thrombolysis in England. Such undertreatment may have medicolegal implications.

\section{$\mathrm{CJB}$ is an intermediate British Heart Foundation fellow.}

1 ISIS-2 (Second International Study of Infarct Survival) Collaborative Group. Randomised trial of intravenous streptokinase, oral aspirin, both or neither among 17187 cases of suspected myocardial infarction: ISIS-2. Lancet

2 Burrell CJ, Mills PG, Rothman MT. In-hospital delav in administration of thrombolstic treatment. Br Heart f 1988;59:606.

3 Office of Population Censuses and Surveys. Mortality statistics 1988: deaths by cause. London: HMSO, 1989. (DH2 89/2.

+ Jagger JD, Murray RG, Davies MK, Littler WA, Flint EJ. Eligibility for thrombolytic therapy in acute myocardial infarction. Lancet $1987 ;$; $34-5$. 5 De Bono D. New drugs for treating myocardial infarction-can we afford them? Cardiology in Practice 1989;7:9-11.

Accepled 25 October 1989

\title{
Attitudes of general practitioners towards their vaccination against hepatitis $B$
}

\section{Paul Kinnersley}

Department of General Practice, University of Manchester, Manchester M13 9PT

Paul Kinnersley, MRCGP, lecturer

Correspondence to: Rusholme Health Centre, Manchester M14 5NP.

Br.Med f 1990;300:238
Reason chosen by 309 general practitioners when asked why they had not been vaccinated against hepatitis $B$

\begin{tabular}{lr}
\hline \multicolumn{1}{c}{ Reason } & No \\
\hline I am at very low risk & 39 \\
I just have not got round to it & 249 \\
I do not trust the vaccine & 3 \\
$\begin{array}{l}\text { Vaccination is of no proved } \\
\text { benefit }\end{array}$ & 4 \\
Other & 14 \\
\hline
\end{tabular}

Between 1980 and 1984, 6696 cases of acute hepatitis B were reported in England, Wales, and Northern Ireland, of which $361(5 \cdot 4 \%)$ occurred in health service staff.' The disease has particular implications for health workers as $5-10 \%$ of those infected become carriers.' This may put them at risk of infecting patients and their own families.

In 1987 the BMA recommended that health care workers who are in contact with patients or handle body fluids and pathological specimens should be immunised against hepatitis $\mathrm{B} .{ }^{3}$ General practitioners handle patients and also come into contact with body fluids when taking blood samples, obtaining microbiological specimens and cervical smears, and doing minor surgery. The need for general practitioners to be vaccinated against hepatitis $B$, however, has not been established, and there is no evidence that general practitioners or other members of primary health care teams are at greater risk of infection than the general population.

Richards described the difficulties that general practitioners experience when seeking health care and noted their failure to make use of preventive medicine. Chambers has called for urgent reform of the provision of health care for general practitioners ${ }^{s}$ and suggested that a preventive service should be offered. I determined the proportion of general practitioners who had been vaccinated against hepatitis $B$ as a means of assessing the need for better preventive health care for general practitioners.

\section{Subjects, methods, and results}

I posted a qutstionnaire to all 699 general practitioners on the list of Lancashire Family Practitioner Committee in January 1989. I sent a single reminder to those who did not reply. The doctors were asked whether they thought that general practitioners should be vaccinated against hepatitis $B$ and whether they themselves had been vaccinated. Doctors who had not been vaccinated were asked to choose one of four possible reasons why not (table).
I received completed questionnaires from 598 general practitioners $(86 \%), 528$ of whom believed that all general practitioners should be vaccinated against hepatitis B. Only 287 , however, had been vaccinated against hepatitis $\mathrm{B}$ or were in the process of being vaccinated; two did not state whether they had been vaccinated. There were no significant differences in the proportion who had been vaccinated between male and female doctors or among different age groups or different areas of practice. Of the 309 respondents who had not been vaccinated, 249 chose the reason "I just have not got round to it" (table). Fourteen thought that none of the four reasons applied. Again, there were no significant differences by sex, age, or area of practice of the doctors.

\section{Comment}

Though the need for general practitioners to be vaccinated against hepatitis B has not been determined, the general practitioners in this study believed that they should be vaccinated. Only half of them had been, however, with most of the others choosing the reason "I just have not got round to it." This suggests either that the doctors do not really believe they need the vaccination or that they experience difficulty in taking up this preventive health measure. As only 39 chose the reason "I am at very low risk" difficulty in getting vaccinated seems to be more likely.

General practitioners may not need to be vaccinated against hepatitis $B$, but the discrepancy between the belief that they do and their prevalence of vaccination needs addressing. Whether general practitioners should be vaccinated needs to be established; if they do, effective structure to promote this is needed. If they do not they should be informed of this to reduce any anxiety about their health care.

I thank Lancashire Family Practitioner Committee and its general practitioners for cooperation with this study and Professor David Metcalfe for his advice and support.

I Polakoff S. Acute viral hepatitis B: laboratory reports $1980-84$. Br Med $\mathcal{F}$ 1986;293:37-8.

Zuckerman AJ. Hepatitis viruses. In: Weatherall D, Ledingham JG, Warrell DA, eds. The Oxford textbook of medicine. Oxford: Oxford University Press, 1987:116-23.

3 British Medical Association. Immunisation against hepatitis B. London: BMA, 1987.

4 Richards C. The heulth of doctors. London: King's Fund, 1989

5 Chambers RM. The health of general practitioners: a cause for concern? f R Coll Gen Pract 1989;39:179-81.

(Accepted 8 November 1989 